\title{
Joining Methods of Analytic Hierarchy Process (AHP), Kano Model and Quality Function Deployment (QFD) to Improve the Tractor's Seat Design for Tractor Drivers in Bangladesh
}

\author{
Rafat Mahmud Hridoy, Md. Shohel Parvez, Nourin Mohsin \\ Department of Industrial Engineering and Management (IEM), Khulna University of Engineering \& Technology (KUET), \\ Khulna, Bangladesh \\ Email: rafathridoy1@iem.kuet.ac.bd,msp.ipe@kuet.ac.bd, ahonanourin27@gmail.com
}

How to cite this paper: Hridoy, R. M., Parvez, Md. S., \& Mohsin, N. (2020). Joining Methods of Analytic Hierarchy Process (AHP), Kano Model and Quality Function Deployment (QFD) to Improve the Tractor's Seat Design for Tractor Drivers in Bangladesh. American Journal of Industrial and Business Management, 10, 1073-1083. https://doi.org/10.4236/ajibm.2020.105071

Received: April 14, 2020

Accepted: May 26, 2020

Published: May 29, 2020

Copyright $\odot 2020$ by author(s) and Scientific Research Publishing Inc. This work is licensed under the Creative Commons Attribution International License (CC BY 4.0).

http://creativecommons.org/licenses/by/4.0/

\begin{abstract}
Nowadays, many product development projects fail as for not meeting customer's expectations up to the mark as product development process is conducted very unsystematically and results in waste of resources. Customer requirement and satisfaction measurement is a major challenge which can be achieved through various methods. This paper presents joining methods of Analytic Hierarchy Process (AHP), Kano Model and Quality Function Deployment to improve the Tractor's Seat design for tractor driver's in Bangladesh in terms of ergonomic and user's needs. A survey was done to 50 Tractor drivers to identify problems of the current seat. By analyzing the data identified the customer requirements and ranked it using AHP. With that Kano questionnaires were developed and answered by 50 tractor drivers. After that, with the integration of Kano model, QFD process was carried out to determine the customer requirement weight and the technical requirement weight to develop a modified design. At the end of the study, it was found out that both methods were able to prioritize the modification elements to be implemented into the new ergonomically designed tractor seat. Still there are some limitations. The analysis was performed based on 50 tractor drivers. For more correct results, more than 50 drivers could be taken into account.
\end{abstract}

\section{Keywords}

Expectations, Unsystematically, Tractor, AHP, Kano, House of Quality

\section{Introduction}

In the past, many researches were occurred about Kano Model and QFD inte- 
gration approach for Ergonomic Design Improvement. This present study provides the data of tractor driver requirements and discusses about the AHP ranking procedure of those requirements and Kano Model and QFD integration approach for Ergonomic Design Improvement. A research work discussed the procedure of Kano questionnaire development and Kano questionnaire result using different formulas for calculating customer satisfaction and dissatisfaction to grade the customer requirements and also focused on the house of quality and Kano integration for ergonomic design improvement (Adila \& Siti, 2012). Another study found out about customer satisfaction as a function of competitive advantage by discussing customer satisfaction and market share and customer satisfaction and loyalty. Authors discussed the Kano's model of customer satisfaction. By discussing identification of product requirements, analysing customer problems instead of customer desires, construction of the Kano questionnaire, administering customer interviews, evaluation and interpretation, evaluation according to frequencies, customer satisfaction coefficient and quality improvement index they showed the customer satisfaction and dissatisfaction. Further they discussed about the quality function deployment to develop projects more successfully (Kurt \& Hans, 1998).

Another analysis focused on the notion of customer satisfaction based on the Kano model and points to the importance of product innovation in exceeding customer satisfaction. It further proposed a combined process model for innovative product development by integrating Kano's model and the quality function deployment (QFD) technique (Shen, Tan, \& Xie, 2000). Again a study points out a method for integration of the Kano model in Quality Function Deployment with 289 potential consumers of draft beer mugs. In this study the integration of the Kano model in the QFD allowed innovative requirements to receive the necessary attention in the product's development process. It also showed the development of a new mug of draft beer (Tontini, 2007).

Additional research work combined rough set theory, Kano model and AHP for determining the final importance of the customer requirement. Firstly the research used the relative reduction and relative core in rough set theory to build a system to acquire customer requirement. Then, depending on relative positive field in rough set, the decision system was made plainer and its corresponding new decision system was initiated to determine the fundamental importance ratings of customer requirement. Then by integrating scale method into AHP approach, calculating formulas a new CR was developed. Further for every CR based on anintegration of its rudiment importance rating, the rating of obtaining the improvement ratio of its satisfaction estimation and "its sales point", the final importance rating was calculated (Li et al., 2009). Kano model also plays an important role in quality management in matrix planning and that was shown in various researches (Tan \& Shen, 2000).

Some studies analyzed that in case of understanding customer satisfaction Kano model is very essential as the model classifies the requirements in important three kinds of categories. The studies further point out its importance in 
fulfilling customer defined quality and customer needs by quantitative method (Berger, Blauth, \& Boger, 1993; Wang \& Ji, 2010). Kano model is also essential in designing multiple product design activities and it is possible by integrating Kano model into quality function development. Combination of fuzzy Kano and fuzzy AHP optimize variety of products for smart cameras. These characteristics were focused on some research works (Yesim, Paul, \& Erol, 2007; Chih-Hsuan \& Juite, 2014; Chaudha, Jain, \& Singh, 2011). Authors worked together to implement Kano. They used various processes to ensure that Kano model actually can delight customers and discussed about how the model does so (Sauerwein et al., 1996).

\section{Sample Population}

The age of the drivers was between 24 years and 40 years, the mean of their age being 32 years. Only male drivers were taken as sample population as no female driver was found. Sample size was calculated by using Equation (1), (Odunaiya, Owonuwa, and Oguntibeju, 2014). So, $n=$ anticipated sample size, $N=$ population size, and $e=$ accuracy level. In this study, $N=55, e=5 \%$ at $95 \%$ confidence level.

$$
n=N /\left(1+N e^{2}\right)
$$

From the equation, the minimum acceptable sample size was calculated to be 48 or more. The available driver number is 50 having no physical problems and the probability of inappropriate measurements of data or unsuitable data deviation was reduced.

\section{Methodology}

Figure 1 illustrates the main procedure of the overall research work.

\subsection{AHP Procedure}

The procedure for using the AHP can be summarized as:

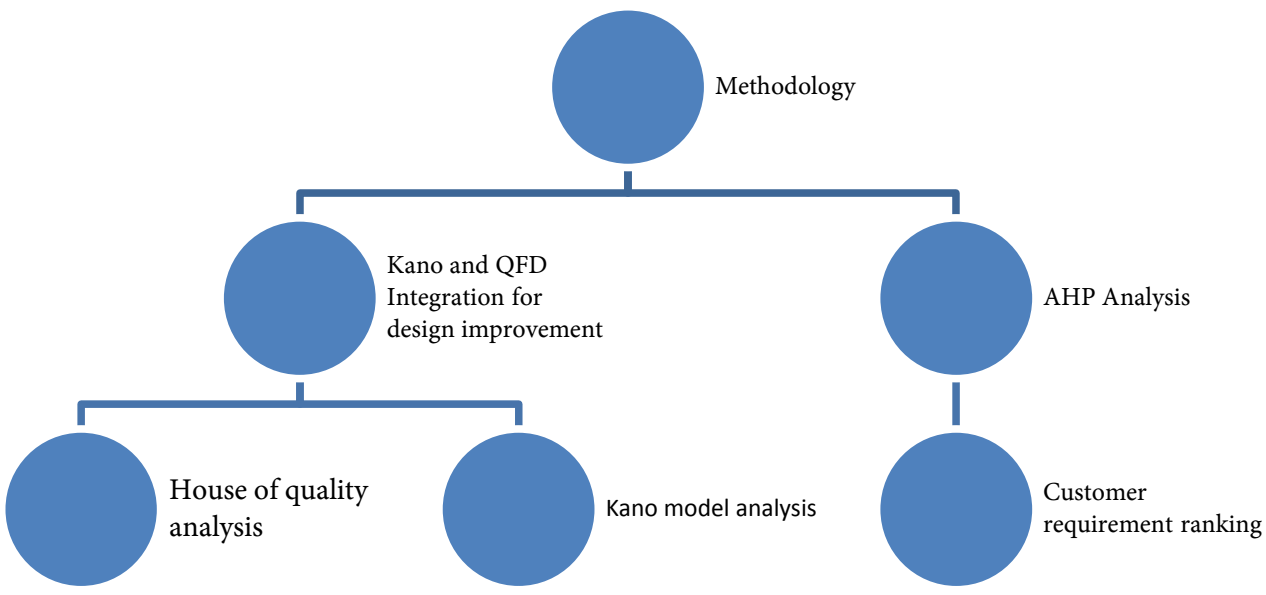

Figure 1. Total methodology flow chart. 
1) Model the problem as a hierarchy containing the decision goal, the alternatives for reaching it, and the criteria for evaluating the alternatives.

2) Establish priorities among the elements of the hierarchy by making a series of judgments based on pairwise comparisons of the elements.

3) Synthesize these judgments to yield a set of overall priorities for the hierarchy.

4) Check the consistency of the judgments.

5) Come to a final decision based on the results of this process.

Table 1 shows scale of pairwise comparison where the analytic hierarchy process and how AHP can be used in making a decision was discussed (Saaty, 1990).

\subsection{Kano Model Procedure}

\subsubsection{Kano Questionnaire Development}

The Kano questionnaire was developed by direct user contact through interview. A survey consisting of 50 tractor drivers was taken. They gave their opinions regarding the current workstation. All relevant comments and suggestions regarding ergonomic consideration were included in the questionnaire. The language used in the questionnaire was clear and understandable. The questions included in the questionnaire were very much clear and unambiguous. Moreover, unbalanced answering options were avoided and the answers were taken from the survey in such a way so that they could be evaluated directly.

- The effective questionnaires response rate was 97\%. Cronbach alpha values for the questionnaire were between 0.70 and 0.85 which means the questionnaire is reliable to be used in this study (Piaw, 2006).

Table 2 shows sample demographic data which was obtained during the survey.

Table 1. Scale of pair wise comparison in AHP.

\begin{tabular}{cc}
\hline Intensity of relative importance & Definition \\
\hline 1 & Equal importance \\
3 & Moderate importance \\
5 & Strong importance \\
7 & Very strong importance \\
9 & Extreme/Absolute importance \\
\hline
\end{tabular}

Table 2. Samples demographic data.

\begin{tabular}{ccc}
\hline Age & Gender & Frequency \\
\hline $20-25$ & Male & 5 \\
$25-30$ & Male & 15 \\
$30-40$ & Male & 30 \\
\hline
\end{tabular}




\subsubsection{Kano Questionnaire Result}

All qualities are measured and classified in six categories; Must-be $(M)$, Attractive $(A)$, One-dimensional $(O)$ and Indifferent $(I)$, Reversible $(R)$, Questinable $(Q)$. Indifferent category is defined as users do not care whether the quality is present or not. This type of quality does not affect user satisfaction at all. A solution was suggested in identifying relative values of meeting user satisfaction or not (Berger, Blauth, \& Boger, 1993).

$$
\begin{gathered}
\text { Customer satisfaction, } \mathrm{CS} \text { (better) }=A+O /(A+O+M+I) \\
\text { Customer dissatisfaction, } \mathrm{CD} \text { (worse) }=O+M /(A+O+M+I)
\end{gathered}
$$

Based on above equations, it would be easier to identify whether qualities offered will fulfill user satisfaction or lead the user towards dissatisfaction. According to (Wang \& Ji, 2010), calculating CS and CD values can reflect the average impacts of each quality provided to customer feeling of satisfaction.

\subsection{House of Quality (HOQ)}

The House of Quality is a voice of customer analysis tool and a key component of the Quality Functional Deployment technique. It starts with the voice of the customer. It is a tool to translate what the customer wants into products or services that meet the customer wants in terms of engineering design values by way of creating a relationship matrix.

* Typically the first chart used in Quality Function Deployment.

* Data intensive and is capable of capturing large amounts of information.

* Left side: has the customer's needs.

* Ceiling: has the design features and technical requirements.

* The Roof: a matrix describing the relationship between the design features.

* Competitive Section: based primarily on the customer's perspective.

* Lower level/Foundation: Benchmarking \& target values used to rank the "hows".

\section{Data Analysis}

\subsection{AHP Analysis}

AHP analysis was done to rank the customer requirements which were obtained from a survey of 50 tractor drivers.

Figure 2 illustrates the pairwise comparison result of customer requirements. To get the result, all the requirements of tractor seat were placed in both row and column by keeping the same sequence number. Then the comparisons were carried out according to the questionnaire result (Saaty, 1990; Saaty, 2008).

Figure 3 was obtained by following the method described by (Saaty, 1990; Saaty, 2008) on how to make pairwise comparison of customer requirements and determine the rank of $\mathrm{CR}$.

Figure 3 clearly depicts that Seat belt with the highest $22.91 \%$ weight obtained the $1^{\text {st }}$ rank position. Backrest with $17.41 \%$ weight obtained the $2^{\text {nd }}$ rank position. Seat surface with $13.75 \%$ weight obtained the $3^{\text {rd }}$ rank position. Adjustable seat 


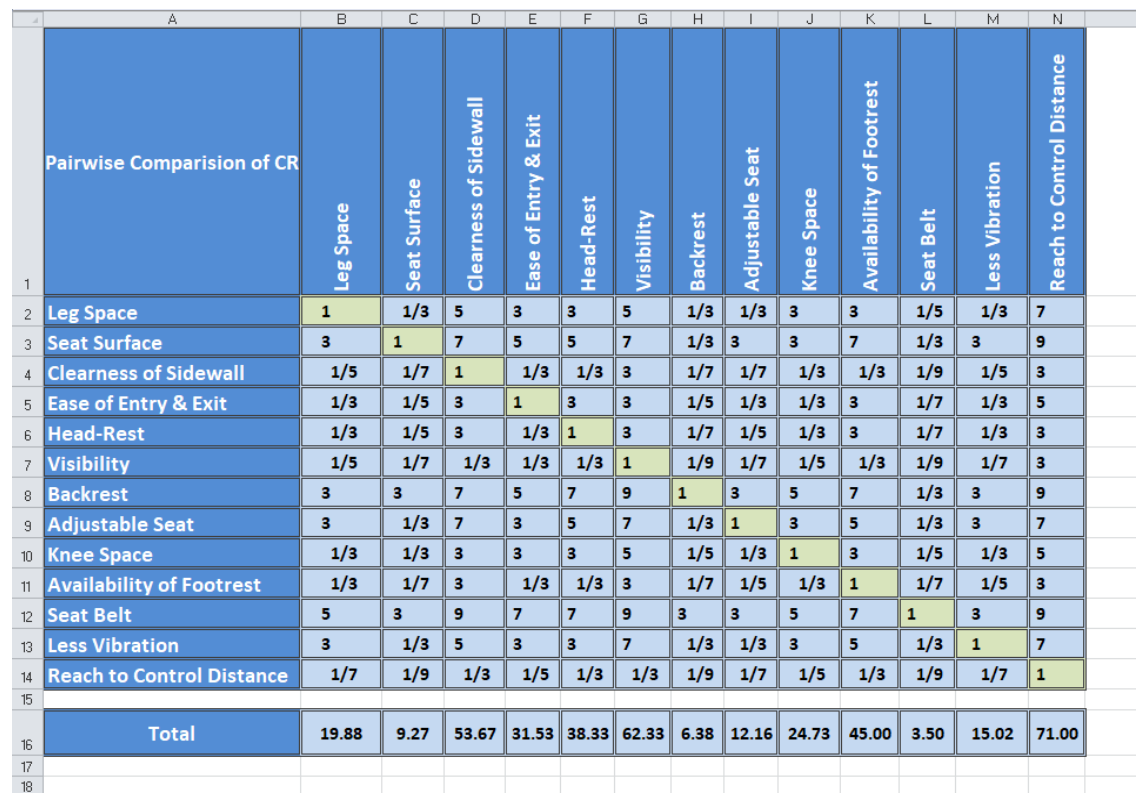

Figure 2. Pairwise comparison of customer requirements.

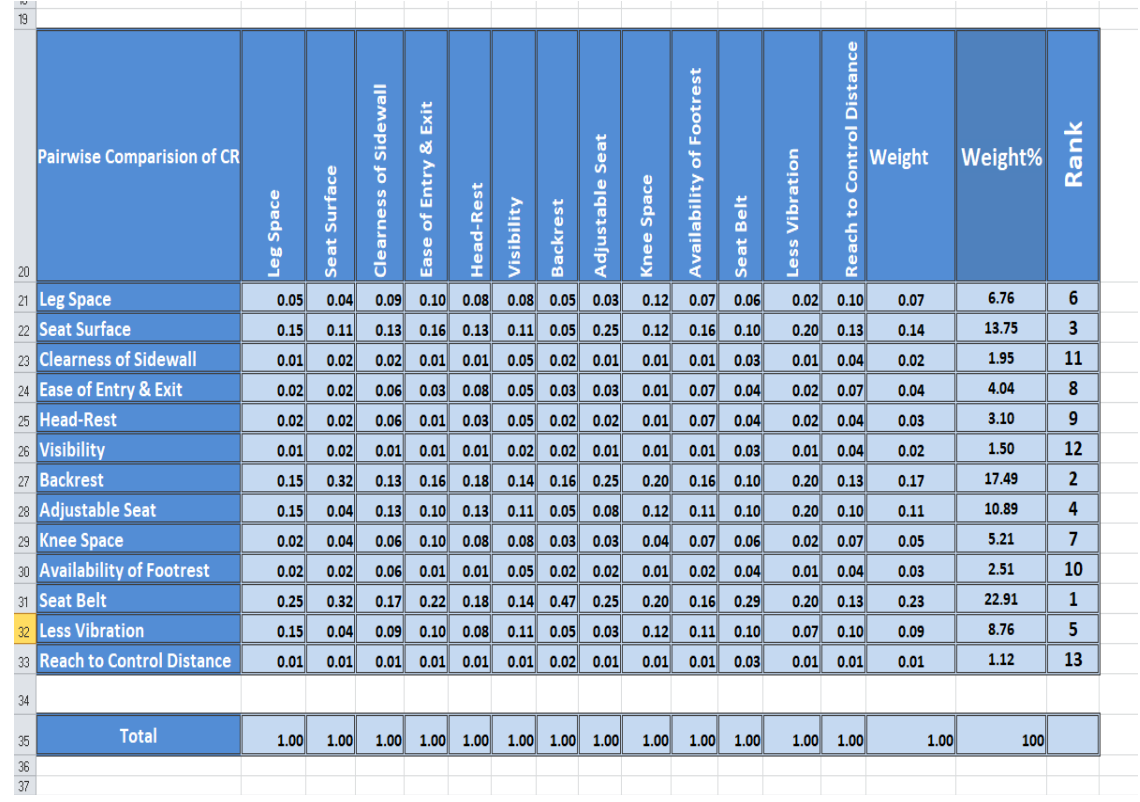

Figure 3. Showing ranking of customer requirement.

with $10.89 \%$ weight obtained the $4^{\text {th }}$ rank position. Less vibration with $8.76 \%$ weight obtained the $5^{\text {th }}$ rank position. Leg space with $6.76 \%$ weight obtained the $6^{\text {th }}$ rank position. Knee space with $5.21 \%$ weight obtained the $7^{\text {th }}$ rank position. Ease of entry and exit with $4.04 \%$ weight obtained the $8^{\text {th }}$ rank position. Head rest with $3.1 \%$ weight obtained the $9^{\text {th }}$ rank position. Availability of foot rest with $2.51 \%$ weight obtained the $10^{\text {th }}$ rank position. Clearance of side wall with $1.95 \%$ weight obtained the $11^{\text {th }}$ rank position. Visibility with $1.5 \%$ weight obtained the $12^{\text {th }}$ rank position. Reach to control distance with $1.12 \%$ weight obtained the $13^{\text {th }}$ rank position. 
A research was conducted on how to determine the consistency index (CI), random index (RI) and consistency ratio (CR) after completing a pairwise comparison of factors. The following calculation was done to determine consistency index, Random index and consistency ratio.

The consistency ratio was obtained in Figure 4 by following the procedure used in (Youssef, 2015). Even if AHP has a consistent system, result will depend on decision maker. For this purpose a consistency ratio must be calculated. CR was found in Microsoft excel which was 0.07.

Formula of $\mathrm{CR}=\mathrm{CI} / \mathrm{RI}$.

Where $\mathrm{CI}=$ Consistency index.

And RI = Random index.

\subsection{Kano Model Analysis}

Kano analysis was done to determine the customer satisfaction (CS) and dissatisfaction (CD). Every requirement was categorized into five categories. For every requirement, fifty tractor drivers vote were considered.

Figure 5 depicting the analysis of Kano model was obtained through a calculation procedure followed by (Adila \& Siti, 2012). Here, the highest customer satisfaction was obtained for seat belt which is 0.90 and highest customer dissatisfaction was obtained for adjustable seat which is 0.86 . Here there was no vote found in Q category.

\subsection{House of Quality}

The QFD matrix can be developed by integrating Kano model. This approach was carried through a research by (Tan \& Shen, 2000). By setting all customer

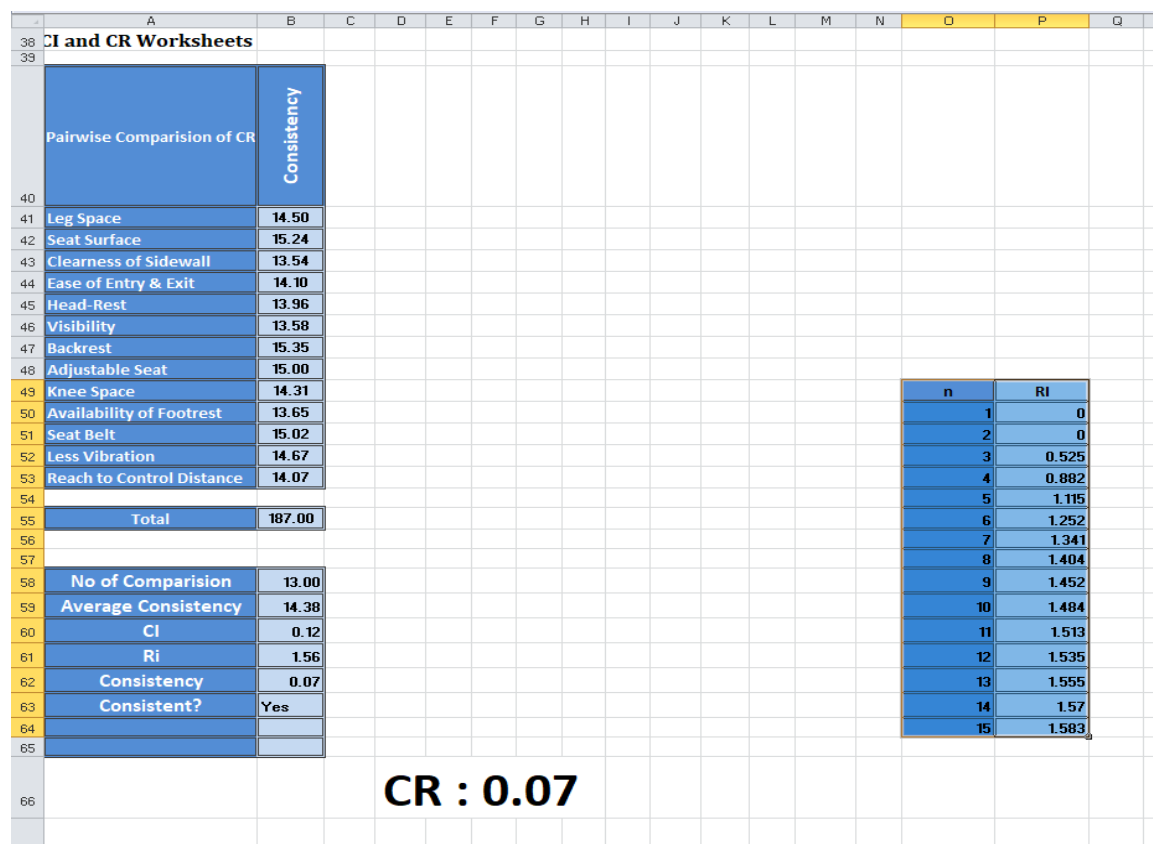

Figure 4. Showing consistency ratio. 


\begin{tabular}{|c|c|c|c|c|c|c|c|c|c|c|c|}
\hline 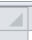 & A & B & c & D & E & $\mathrm{F}$ & G & H & 1 & 1 & K \\
\hline \multicolumn{12}{|l|}{1} \\
\hline 2 & & & & \multicolumn{3}{|c|}{ KANO MODEL } & & & & & \\
\hline \multicolumn{11}{|l|}{3} & \\
\hline 4 & Customer's Requirement & A & M & 0 & $\mathrm{i}$ & $\mathbf{R}$ & $\mathbf{Q}$ & Total & CS & CD & \\
\hline 5 & Leg Space & 5 & 22 & 17 & 5 & 1 & & 50 & 0.45 & 0.80 & \\
\hline 6 & Seat Surface & 8 & 6 & 28 & 8 & & & 50 & 0.72 & 0.68 & \\
\hline 7 & Clearness of Sidewall & 12 & 4 & 8 & 24 & 2 & & 50 & 0.42 & 0.25 & \\
\hline 8 & Ease of Entry \& Exit & 14 & 3 & 20 & 13 & & & 50 & 0.68 & 0.46 & \\
\hline 9 & Reach to Control Distance & 17 & 9 & 13 & 9 & 2 & & 50 & 0.63 & 0.46 & \\
\hline 10 & Adjustable Seat & 4 & 26 & 17 & 3 & & & 50 & 0.42 & 0.86 & \\
\hline 11 & Backrest & 19 & 7 & 23 & 1 & & & 50 & 0.84 & 0.60 & \\
\hline 12 & Visibility & 12 & 6 & 24 & 8 & & & 50 & 0.72 & 0.60 & \\
\hline 13 & Knee Space & 20 & 6 & 8 & 16 & & & 50 & 0.56 & 0.28 & \\
\hline 14 & Availability of Footrest & 22 & 5 & 5 & 16 & 2 & & 50 & 0.56 & 0.21 & \\
\hline 15 & Seat Belt & 36 & 3 & 9 & 2 & & & 50 & 0.90 & 0.24 & \\
\hline 16 & Less Vibration & 13 & 5 & 25 & 7 & & & 50 & 0.76 & 0.60 & \\
\hline 17 & Head-Rest & 12 & 2 & 22 & 14 & & & 50 & 0.68 & 0.48 & \\
\hline \multicolumn{12}{|l|}{18} \\
\hline 19 & & & \multicolumn{2}{|c|}{ Where, } & & & & & & & \\
\hline 20 & & & \multicolumn{4}{|c|}{$\mathrm{CS}=$ Customer Satisfaction } & & & & & \\
\hline 21 & & & \multicolumn{5}{|c|}{$C D=$ Customer Dissatisfaction } & & & & \\
\hline
\end{tabular}

Figure 5. Kano model analysis.

requirements, absulate weight and absulate importance in the rows, the engineering characteristics as well as kanocategory, $\mathrm{k}$ value, user satisfaction, user satisfaction target, adjustment factor, improvement ratio, adjusted improvement ratio and adjustment importance were placed in columns to build the QFD matrix. Table 3 represented ratings for different criterions and Table 4 shows ratings for various relationships (Tan \& Shen, 2000).

Figure 6 shows the overall house of quality required for the purpose of the study (Tan \& Shen, 2000). For against all the customer requirements, some technical requirements were established and at the very right end customer requirement (adjustment importance) weight were obtained and at the bottom technical requirement (absolute importance) were obtained. Seat belt obtained the highest customer requirement weight and clearance of side wall obtained the lowest weight. On the other hand dimension obtained the highest technical requirement weight and material thickness obtained the lowest. The ratings for various characteristics on different criterions were derived from above mentioned tables.

\section{Result and Discussion}

In this paper, all Customer requirements were properly ranked through AHP. All the CS and CD rate were obtained from Kano model analysis. QFD approach uses customer importance ratings and customer satisfaction to establish priorities. The integration of Kano model and QFD clearly identifies the customer requirement weight and the technical requirement weight to develop a modified design. Nowadays, many researchers are conducting their research through the 
Table 3. Importance scale.

\begin{tabular}{cc}
\hline Criteria & Rating \\
\hline Very Less Important & 1 \\
Less Important & 2 \\
Moderately Important & 3 \\
Important & 4 \\
Most Important & 5 \\
\hline
\end{tabular}

Table 4. Relationship scale.

\begin{tabular}{cc}
\hline Criteria & Rating \\
\hline Weak & 1 \\
Moderate & 3 \\
Strong & 5 \\
\hline
\end{tabular}

HoQ

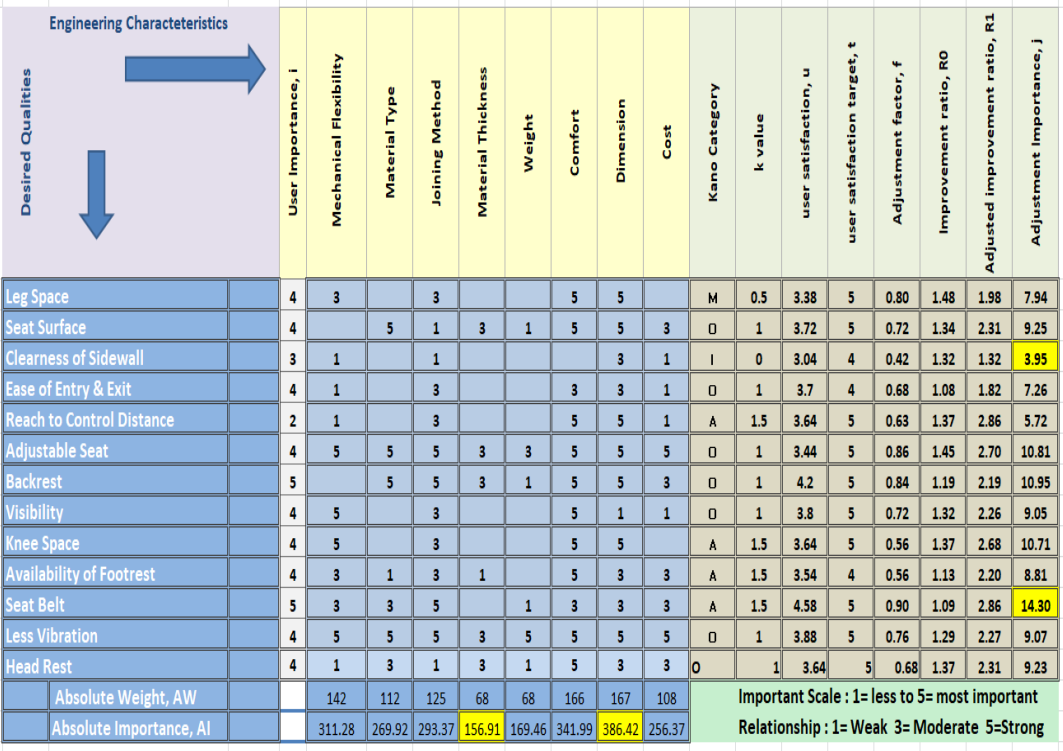

Figure 6. House of quality.

joining methods of Kano model and quality function deployment to improve product or workstation design considering customer requirements (Shen, Tan, \& Xie, 2000; Hashim \& Dawal, 2012; Tontini, 2007).

It was discovered that ergonomics was the main factor in engineering characteristic in developing a new or modified product nowadays. Most of the tractor drivers feel the necessity of a seat belt while driving tractor. They also feel the importance of less vibration, head rest, adjustable seat, knee space and back rest largely as they think these requirements in a tractor seat will definitely increase their performance. While fulfilling the customer requirements through technical 
requirements, dimension obtained the highest technical weight as it is closely related to these customer requirements.

\section{Future Scope}

The study was conducted by taking a small sample size. In the future, this type of study could be conducted for a large sample size for the betterment of accuracy of the result. Also, the tractor seat could be designed ergonomically by keeping the findings of the study in mind.

\section{Conflicts of Interest}

The authors declare no conflicts of interest regarding the publication of this paper.

\section{References}

Adila, M. H., \& Siti, Z. M. D. (2012). Kano Model and QFD Integration Approach for Ergonomic Design Improvement. Social and Behavioral Sciences, 5, 22-32. https://doi.org/10.1016/j.sbspro.2012.09.1153

Berger, C., Blauth, R., \& Boger, D. (1993). Kano's Method for Understanding Customer-Defined Quality. Center for Quality of Management Journal, 2, 3-35.

Chaudha, A., Jain, R., \& Singh, A. R. (2011). Integration of Kano's Model into Quality Function Deployment (QFD). The International Journal of Advanced Manufacturing Technology, 53, 689-698. https://doi.org/10.1007/s00170-010-2867-0

Chih-Hsuan, W., \& Juite, W. (2014). Combining Fuzzy AHP and Fuzzy Kano to Optimize Product Varieties for Smart Cameras: A Zero-One Integer Programming Perspective. Applied Soft Computing, 22, 410. https://doi.org/10.1016/j.asoc.2014.04.013

Hashim, A. M., \& Dawal, S. Z. M. (2012). Kano Model and QFD Integration Approach for Ergonomic Design Improvement. Procedia-Social and Behavioral Sciences, 57, 22-32. https://doi.org/10.1016/j.sbspro.2012.09.1153

Kurt, M., \& Hans, H. H. (1998). How to Make Product Development Projects More Successful by Integrating Kano's Model of Customer Satisfaction into Quality Function Deployment. Technovation, 18, 25-38. https://doi.org/10.1016/S0166-4972(97)00072-2

Li, Y. L. et al. (2009). An Integrated Method of Rough Set, Kano's Model and AHP for Rating Customer Requirements' Final Importance. Expert Systems with Applications, 3, 7045-7053. https://doi.org/10.1016/j.eswa.2008.08.036

Odunaiya, N. A., Owonuwa, D. D., \& Oguntibeju, O. O. (2014). Ergonomic Suitability of Educational Furniture and Possible Health Implications in a University Setting. Advances in Medical Education and Practice, 5, 1-14.

https://doi.org/10.2147/AMEP.S38336

Piaw, C. Y. (2006). Asas Statistik Penyelidikan: Kaedahdan Statistik Penyelidikan. Kuala Lumpur: McGraw Hill.

Saaty, T. L. (1990). How to Make a Decision: The Analytic Hierarchy Process. European Journal of Operational Research, 48, 9-26.

https://doi.org/10.1016/0377-2217(90)90057-I

Saaty, T. L. (2008). Decision Making with the Analytic Hierarchy Process. International Journal of Services Sciences, 1, 83-98. https://doi.org/10.1504/IJSSCI.2008.017590

Sauerwein, E., Bailom, F., Matzler, K., \& Hinterhuber, H. (1996). The Kano Model: How 
to Delight Your Customers. In International Working Seminar on Production Economics (pp. 19-23).

Shen, X. X., Tan, K. C., \& Xie, M. (2000). An Integrated Approach to Innovative Product Development Using Kano's Model and QFD. European Journal of Innovation Management, 3, 91-99. https://doi.org/10.1108/14601060010298435

Tan, K. C., \& Shen, X. X. (2000). Integrating Kano's Model in the Planning Matrix of Quality Function Deployment. Total Quality Management, 11, 1141-1151. https://doi.org/10.1080/095441200440395

Tontini, G. (2007). Integrating the Kano Model and QFD for Designing New Products. Total Quality Management \& Business Excellence, 18, 599-612. https://doi.org/10.1080/14783360701349351

Wang, T., \& Ji, P. (2010). Understanding Customer Needs through Quantitative Analysis of Kano's Model. International Journal of Quality \& Reliability Management, 27, 173-184. https://doi.org/10.1108/02656711011014294

Yesim, S., Paul, K., \& Erol, O. (2007). Integration of Kano's Model Into QFD for Multiple Product Design. IEEE Transactions on Engineering Management, 54, 380-390. https://doi.org/10.1109/TEM.2007.893990

Youssef, A. M. (2015). Landslide Susceptibility Delineation in the Ar-Rayth Area, Jizan, Kingdom of Saudi Arabia, Using Analytical Hierarchy Process, Frequency Ratio, and Logistic Regression Models. Environmental Earth Sciences, 73, 8499-8518.

https://doi.org/10.1007/s12665-014-4008-9 